\title{
1 Construction and validation of a mCherry protein vector for promoter analysis in
}

2

3

4

$5{ }^{1}$ Departamento de Microbiología Molecular y Biología de las Infecciones, Centro de

6 Investigaciones Biológicas (CIB-CSIC), Ramiro de Maeztu 9, 28040 Madrid, Spain.

$7 \quad{ }^{2}$ Departmento de Biotecnología y Microbiología de Alimentos, Instituto de

8 Investigación en Ciencias de la Alimentación CIAL (CSIC-UAM), 28049 Madrid, Spain.

$11{ }^{\mathrm{a}}$ Authors contributed equally to the work.

$12{ }^{\mathrm{b}}$ Current address: Host-Microbe Interactomics, Wageningen University, Animal

13 Sciences, Animal Sciences Department, P.O. BOX 338, 6700 AH, Wageningen, The

14 Netherlands.

*Corresponding author. Mailing address: Departamento de Biotecnología y

17 Microbiología de Alimentos, Instituto de Investigación en Ciencias de la Alimentación

CIAL (CSIC-UAM), Nicolás Cabrera 9, 28049 Madrid, Spain. Phone: +34910017900; 


\section{Abstract}

22 Lactobacilli are widespread in natural environments and are increasingly being

23 investigated as potential health modulators. In this study we have adapted the broad-

24 host range vector pNZ8048 to express the mCherry protein (pRCR) to expand the usage

25 of the mCherry protein for analysis of gene expression in Lactobacillus. This vector is

26 also able to replicate in Streptococcus pneumoniae and E. coli. The usage of pRCR as a

27 promoter probe was validated in Lactobacillus acidophilus by characterizing the

28 regulation of lactacin $\mathrm{B}$ expression. The results show that the regulation is exerted at the

29 transcriptional level, with $l b a B$ gene expression being specifically induced by co-culture

30 of the L. acidophilus bacteriocin producer and the Streptococcus thermophilus STY-31

31 inducer bacterium.

34 Keywords Lactobacillus; broad host-range vector; pRCR, bacteriocin; promoter 35 regulation. 
Lactobacilli belong to the lactic acid bacteria (LAB) group, and traditionally they have been used for fermented food production. They are widespread in natural environments including niches such as the human and animal gastrointestinal tracts, where they can play important roles as health modulators $[2,23]$. Thus, they are increasingly used as functional food ingredients (probiotics), and as vectors for live oral vaccines and drugs $[3,24,25]$. Several Lactobacillus species have been identified to produce bacteriocins, some of them have a dual role, acting as inhibitors at high concentrations and participating in interspecies communication or bacterial cross talk [8]. could also facilitate the monitoring of these bacteria in biofilm formation and interaction with the host. In addition, fluorescent proteins are used as reporters for transcriptional gene expression and regulation. In our previous work we designed a $m r f p$ gene codon, optimized for expression in Gram-positive bacteria, from the monomeric variant of the 'mCherry' red fluorescent protein (RFP) from Dicosoma sp. [11]. Its use as a reporter in Lactococcus lactis and Enterococcus faecalis was validated by the construction and testing of shuttle vectors based on the pAK80 plasmid [11]. Additional applications of the mCherry-derived vectors in these LAB species have been recently reported $[4,5]$. In this study we have constructed a vector based on the pSH71 replicon [7, 12], in order to expand the usage of mCherry for analysis of gene expression in Lactobacillus and its usage as a promoter probe validated in L. acidophilus. 
Materials and methods

Bacterial strains and culture conditions

L. acidophilus CECT 903 from the Colección Española de Cultivos Tipo (Paterna, Spain) and L. acidophilus La5 (Chr. Hansen, Hørsholm, Denmark) strains were grown in MRS broth (Pronadisa, Madrid, Spain) supplemented with $0.05 \%$ L-cysteine hydrochloride (Calbiochem, Merck KGaA, Darmstadt, Germany) and 0.2\% Tween 80 (Oxoid, Hampshire, UK) (MRSCT) at $37^{\circ} \mathrm{C}$. S. thermophilus STY-31 (Chr. Hansen) was grown in ESTY broth (Pronadisa) supplemented with $0.5 \%$ glucose at $37^{\circ} \mathrm{C}$. Escherichia coli DH-5 [21] was grown in Luria-Bertani broth at $37{ }^{\circ} \mathrm{C}$ with vigorous shaking. Streptococcus pneumoniae 708 [18] was grown in AGCH medium [17] supplemented with $0.25 \%$ yeast extract and $0.8 \%$ sucrose at $37{ }^{\circ} \mathrm{C}$ without shaking When necessary, chloramphenicol (Sigma-Aldrich, St. Louis, MO, USA) was added to the culture medium at a final concentration of $10 \mu \mathrm{g} \mathrm{mL}^{-1}$ for $E$. coli and $5 \mu \mathrm{g} \mathrm{mL}^{-1}$ for S. pneumoniae and L. acidophilus. Plate media were prepared by adding agar (Pronadisa) to liquid broth at a final concentration of $1.5 \%$.

General DNA manipulation and transformation

The promoter-probe vector and the expression plasmid constructed in this work were based on the the $\mathrm{pSH} 71$ replicon $[7,12]$. Plasmid pRCR was constructed as follows (Fig. 1). Plasmid pNZ8048 [16] was digested with $B g l I I$ and $S a c I$ to remove the nisin promoter. The resultant 3168 bp DNA fragment, containing the rolling-circle replicon of the pSH71 plasmid and the chloramphenicol resistance cat gene, was purified from a 0.8\% agarose gel using the QIAquick Gel Extraction Kit (Qiagen Iberia, Madrid, Spain). The $m r f p$ gene encoding the mCherry protein [11] was amplified from plasmid 
pTVCherry (National Collections of Industrial and Marine Bacteria, Aberdeen, UK) by using the specific primers mCherryF (5'-

GGAAGATCTTCCCGAATTCCCCGGGGATCCTCTAGAGGGATACGCACG

AGTTTCAACT-3') and mCherryR (5'-

CGCGAGCTCATTTATATAATTCGTCCATGCCACCTGT-3') to obtain a $801 \mathrm{pb}$ amplicon containing the $m r f p$ gene preceded by the multicloning site $B g l \mathrm{II}, E c o$ RI SmaI, XmaI BamHI, XbaI. The PCR product was then digested with BglII and SacI restriction enzymes and ligated, with T4 DNA ligase (Thermo Fisher Scientific, Waltham, USA), to the 3168 bp fragment from pNZ8048. The resulting plasmid, named pRCR (3960 bp), was established in S. pneumoniae 708 by transformation as previously described [19]. Transformants were selected for chloramphenicol resistance, and the correct nucleotide sequence of the insert, containing a multicloning site and the $m r f p$ gene in pRCR, was confirmed by DNA sequencing at Secugen S.L. (Centro de Investigaciones Biológicas, Madrid, Spain).

The promoter $\left(P_{l b a B}\right)$ of the L. acidophilus La5 lactacin B gene [22] was cloned upstream of $m r f p$ in pRCR, generating the transcriptional fusion $P_{l b a B}-m r f p$ in pRCR11. To this end, an amplicon was generated using the chromosomal DNA of L. acidophilus La5 as template and the primers LBA1797F (5'AGGAGATCTGCGTACAAAGATGTGGTTAA-3') and LBA1797R (5 'AGGTCTAGATGAGATTTTTATCTCATTTCAAC-3') to obtain a 221 pb fragment containing the $P_{l b a B}$ sequence. After digestion with $B g l \mathrm{II}$ and $X b a \mathrm{I}$, the amplicon was introduced into the multicloning site of $\mathrm{pRCR}$, after digestion with the same restriction enzymes. The resulting plasmid pRCR11 (4166 bp) was established in E. coli DH5 $\alpha$ by transformation as described previously by Hanahan [13]. The presence of the transcriptional fusion in pRCR11 was confirmed by DNA sequencing with primers 
LBA1797F and LBA1797R.

Plasmid pRCR11 was transferred to L. acidophilus CECT903 cells by

electrotransformation as follows. The CECT903 strain was grown under aerobic

conditions at $37^{\circ} \mathrm{C}$, without shaking, during $15 \mathrm{~h}$ in MRSCT broth supplemented with

$1 \%$ glycine. Subsequently, $4 \mathrm{~mL}$ of the culture were used to inoculate $200 \mathrm{~mL}$ of the

same fresh medium, and grown until it reached an $\mathrm{OD}_{600}$ of 0.3-0.4. Cells were

collected by centrifugation at $0{ }^{\circ} \mathrm{C}$ and $8600 \times g$ for $10 \mathrm{~min}$ and washed four times with ice-cold electroporation buffer (HEPES 0.1 mM, sucrose 0.5 M, pH 7.5). Finally, cells were resuspended in $1.6 \mathrm{~mL}$ of ice-cold electroporation buffer. $750 \mu \mathrm{L}$ of cells and 0.5 $\mu \mathrm{g}$ of plasmid DNA were used for electrotransformation. The electroporation conditions were $25 \mu \mathrm{F}, 200 \Omega$ and $2.5 \mathrm{kV}$ in a $0.4-\mathrm{cm}$ cuvette, using a Gene Pulser and a Pulse

Controller apparatus (Bio-Rad, Richmond, CA, USA). After electroporation, cells were resuspended in $8 \mathrm{~mL}$ of MRSCT broth supplemented with $10 \mathrm{mM} \mathrm{CaCl}_{2}$ and $0.5 \mathrm{M}$ sucrose, incubated aerobically at $37^{\circ} \mathrm{C}$ for $3 \mathrm{~h}$, without agitation, and then plated onto MRSCT medium supplemented with $1 \%$ agar and chloramphenicol.

Induction assay and determination of fluorescence

Induction of expression of mCherry from the $P_{l b a B}$ promoter in L. acidophilus

CECT903[pRCR11] cells was assayed by co-culturing L. acidophilus

CECT903[pRCR11] with the inducer Streptococcus thermophilus STY-31 strain [22].

Co-cultures were carried out in MRSCT medium inoculated with $2 \%$ each of $L$. acidophilus CECT903 [pRCR11] and S. thermophilus STY-31 overnight cultures. growth were tested simultaneously with the Varioskan Flash system (Thermo Fisher 
measuring OD at $600 \mathrm{~nm}$ and in vivo mCherry expression at an excitation wavelength of $587 \mathrm{~nm}$ and an emission wavelength of $612 \mathrm{~nm}$. Background fluorescence of the control strain (L. acidophilus CECT903 [pRCR11] without S. thermophilus STY-31 grown under the same conditions) was used to normalize the fluorescence signals during cultivation. All measurements were performed in sterile 96-well optical bottomed microplates (Nunc, Rochester, NY, USA) with a final assay volume of $300 \mu$ l per well by using the microtiter plate assay system Varioskan Flash. The microplates were incubated for $24 \mathrm{~h}$ at $37^{\circ} \mathrm{C}$. Measurements were made at $1 \mathrm{~h}$ intervals.

\section{Preparation of nucleic acids}

For cloning and sequencing experiments, plasmidic DNA was purified from E. coli DH$5 \alpha$ by usage of QIAprep Spin Miniprep and Midiprep kits (Qiagen, Hilden, Germany) or from S. pneumoniae 708 as previously described (Mohedano et al., 2005). For primer extension analysis, a culture of L. acidophilus CECT903[pRCR11] and the co-culture of L. acidophilus CECT903 [pRCR11] and S. thermophilus STY-31 were grown to an $\mathrm{OD}_{600}$ of 1.2 and then used for analysis of $m r f p$ mRNA. Total RNA was isolated with a Ribolyser and Recovery kit from Hybaid (Middlesex, United Kingdom) as specified by the supplier. The RNAs were checked for the integrity and yield of the rRNAs by Qubit $^{\mathrm{TM}}$ fluorometer (Invitrogen, Madrid, Spain) and by Gel Doc 1000 (Bio-Rad). The patterns of rRNAs were similar in all preparations.

Primer extension analysis

Primer extension analysis was performed by a modification of the method described by Fekete et al. [10]. The start site of $l b a B$ mRNA was detected using the LBABP primer (5'-TGAGTTGAAACTCGGTGCGTATCCTCT-3') labeled with 6-FAM at its 5' -end 
162 (Sigma-Aldrich). Two hundred pmol of primer were annealed to $40 \mu \mathrm{g}$ of total RNA.

163 Primer extension reactions were performed by incubation of the annealing mixture with 20 nmol each of dNTP (dATP, dGTP, dCTP and dTTP), $200 \mathrm{U}$ of Maxima Reverse Transcriptase (Thermo Fisher Scientific, Madrid, Spain) in $1 \times$ reverse transcriptase buffer (Thermo Fisher) in a final volume of $50 \mu 1$ at $50{ }^{\circ} \mathrm{C}$ for $60 \mathrm{~min}$. Then, the reactions were supplemented with $50 \mu \mathrm{l}$ of TE $(10 \mathrm{mM}$ Tris $\mathrm{HCl} \mathrm{pH} 8.0,1 \mathrm{mM}$ EDTA) and purified by treatment with phenol (vol:vol) for $5 \mathrm{~min}$ at room temperature and ethanol precipitation with three volumes of $100 \%$ ethanol in the presence of $0.3 \mathrm{mM} \mathrm{Na}$ acetate. After overnight storage at $-20^{\circ} \mathrm{C}$, samples were sedimented by centrifugation at $12.000 \times g, 30 \mathrm{~min}$ at $-10^{\circ} \mathrm{C}$ and resuspended in TE $(12 \mu \mathrm{L})$. polyacrylamide gel containing $7 \mathrm{M}$ urea. Bands labeled with 6-FAM were detected and directly quantified with a FujiFilm Fluorescent Image Analyzer FLA-3000 (Fujifilm, Düsseldorf, Germany).

For determination of the length of the extended products, the primer extension reactions were further purified using Agencourt Clean Seq (Beckam Coulter,

178 Alcobendas, Madrid, Spain) and kept frozen at $-20^{\circ} \mathrm{C}$ until use. Samples were separated on an Abi 3730 DNA Analyzer (Applied Biosystems, Tres Cantos, Madrid, Spain) capillary electrophoresis instrument using techniques and parameters recommended by the manufacturer. A DNA sequence of pRCR11 determined by the dideoxynucleotide method with unlabeled LBABP primer was included in the same capillary in each run to determine fragment length. The Peak Scanner version V1.0 (Applied Biosystems) was used to screen the data and identify major peaks.

\section{Results and discussion}


188 Following the construction and analysis of the pTL family of plasmids designed for using mCherry as a reporter in LAB [11], we were unable to transfer any of these plasmids to Lactobacillus casei and L. acidophilus strains nor to S. pneumoniae strains. These pTL plasmids were derived from pAK80, which carries, in addition to the erythromycin resistance marker, two origins of replication, one from the lactococcal plasmid pCT1138 and the other from the E. coli p15A plasmid, and replicates in Grampositive bacteria by the theta mode mechanism [14]. As an alternative, and with the aim of developing new tools for gene expression analysis in lactobacilli, the use of the replicon of the L. lactis pSH71 plasmid [7, 12] was investigated. This plasmid uses the rolling circle-type mechanism for replication, and is characterized by a broad hostrange, which includes Gram-positive bacteria and E. coli. Therefore, a promoter-probe vector (pRCR) and an expression plasmid (pRCR11) carrying the synthetic mrfp gene optimized for LAB [11] and the chloramphenicol resistance marker were constructed (Fig. 1). pRCR was generated by changing a DNA fragment of pNZ4048 containing the potential to be used in various LAB species. 
212 located upstream of the $l b a B$ bacteriocin structural gene from L. acidophilus [22] and carrying the putative promoter $P_{l b a b}$ was cloned upstream of $m r f p$ in pRCR to generate pRCR11. The expression of lactacin B in L. acidophilus has been demonstrated to be inducible by the co-culture with live target bacteria [22]. The mrfp gene was used as reporter to monitor the $P_{l b a B}$ activity during the induction of lactacin B production by the transformation of L. acidophilus CECT 903 with pRCR11. The induction of bacteriocin expression was assayed by co-culturing this strain with $S$. thermophilus STY-31, a previously identified inducer strain [22]. The functional expression of mCherry under the control of $P_{l b a B}$ and the increase of biomass during cell growth was monitored (Fig. 2). The results revealed that the growth of L. acidophilus CECT 903[pRCR11] was very similar in both single and co-cultures. However, the mCherry activity was detected only in the presence of S. thermophilus STY-31. Moreover, under co-culture conditions the increase of mCherry fluorescence correlated with the growth pattern. These results indicated that up-regulation of lactacin B expression initiates during exponential growth as previously demonstrated [22]. The maximum fluorescence levels were detected at the stationary phase $\left(\mathrm{OD}_{600}=1.3\right)$, consequently growth to this phase was used for further experiments.

Transcriptional analysis of the influence of co-culture with $S$. thermophilus on lactacin B expression in L. acidophilus

Our previous quantitative RT-PCR studies of L. acidophilus La5 lbaB gene expression had shown that in the presence of S. thermophilus STY-31 an increase of the lbaB transcript takes place [22]. Thus, total RNA was extracted from L. acidophilus CECT603[pRCR11] cells grown in the presence or absence of S. thermophilus STY-31 to stationary phase and samples were used for primer extension analysis performed with 
a 5-end 6-FAM labeled LBABP primer. Analysis of the same volume $(6 \mu 1)$ of both reactions in a polyacrylamide gel detected the extended products encoded by pRCR11 complementary to the lbaB transcript in L. acidophilus CECT603[pRCR11] grown in the presence or absence of S. thermophilus STY-31 (Fig. 3B). In the absence of the inducer two bands with similar intensity were observed, whereas in the co-cultures one more prominent and two minor longer extended products were observed. The fluorescence of the bands was quantified with a fluorescent image analyzer, and the results revealed a 5-fold induction due to the presence of S. thermophilus STY-31 (Fig. 3B). transcript, the primer extension reactions were also analyzed by capillary unlabelled LBABP primer (Fig. 3A). Since we expected low transcript levels of $P_{l b a B}$ in cells grown in mono-culture, we processed $250 \mathrm{nl}$ for the capillary electrophoresis experiments compared to $40 \mathrm{nl}$ derived from cells grown in co-culture. The pattern of the peaks observed (Fig 3B) correlated with that obtained for the labeled bands in the polyacrylamide gel (Fig. 3A). The two bands detected in cultures of L. acidophilus CECT603[pRCR11] corresponded to extended products of 185 and $187 \mathrm{nt}$, the first being the major band present in the co-cultures (Fig. 3B). This result located the $5^{\prime}$-end of the $l b a B$ mRNA at a $\mathrm{C}$ and A (Fig. 3C), since 6-FAM labeled DNA extended products run as if they were, on an average, three nucleotides shorter than the dideoxy sequencing products (Fekete et al., 2003). Upstream of the start sites, a putative promoter was detected composed of a -35 (TTGtAa) and a -10 (aATAAT), these sequences being characteristic for the binding of the vegetative $\sigma$ factor of the bacterial RNA polymerases with an anomalous (too long) spacing of 24 nt (Fig. 3C). Moreover, 
the two start sites for transcription are included in one of the arms of the inverted repeat characteristic for binding of transcriptional regulators. This location predicts that the binding of a protein to the inverted repeat will impair initiation of transcription catalyzed by the RNA polymerase. The expression of the lactacin B operon is regulated by the response regulator RR_1798 which is part of a three-component regulatory system composed of the inducing peptide IP_1800, the HK_1799 histidine kinase and the $R R \_1798$ response regulator $[1,22]$. Thus, it seems that under uninduced conditions competition between the RNA polymerase and RR_1798 for binding to the upstream region of $l b a B$ gene will result in low levels of the transcript starting at the two nucleotides $\mathrm{G}$ and $\mathrm{C}$. Then, in the presence of bacteria that compete for the environmental niche, HK_1799 would sense its presence and, by modification of the RR_1798, would impair the repression of transcription of $l b a B$ and result in an increase of lactacin B levels. We have previously demonstrated that the production of lactacin B by $L$. acidophilus is controlled by an autoinduction mechanism involving a secreted peptide and by co-culture with live inducer cells [22]. These characteristics of induction of bacteriocin production through autoinduction and co-culture have been recently described to be widespread among bacteriocinogenic L. plantarum strains [20]. The use of mCherry as a promoter probe in pRCR 11 has allowed us to locate the region where the $l b a B$ transcriptional regulation is specifically induced by co-culture of the lactacin $\mathrm{B}$ producer with the inducing bacteria. broadened the host-range in LAB of the mCherry based vectors pTLR. Indeed, the promoter-probe vector $\mathrm{pRCR}$ has demonstrated to be suitable for characterization of complex promoter induction mechanisms such as those related to bacteriocin production by L. acidtophillus. 


\section{Acknowledgements}

289

290

291

292

This study was supported by grants AGL2012-40084-C03-01, AGL2012-35814 and RM2011-00003-00-00 from the Spanish Ministry of Economics and Competitiveness and by European Commission FP7 Initial Training Network (contract 238490). We thank Dr. Stephen Elson for the critical reading of the manuscript. We also thank M. Angeles Corrales for technical assistance.

\section{References}

1. Altermann E, Russell WM, Azcarate-Peril MA, Barrangou R, Buck BL, McAuliffe O, Souther N, Dobson A, Duong T, Callanan M, Lick S, Hamrick A, Cano R, Klaenhammer TR (2004) Complete genome sequence of the probiotic lactic acid bacterium Lactobacillus acidophilus NCFM. Proc Natl Acad Sci USA 102:39063912

2. Bao S, Zhu L, Zhuang Q, Wang L, Xu PX, Itoh K, Holzman IR, Lin J (2013) Distribution dynamics of recombinant Lactobacillus in the gastrointestinal tract of neonatal rats. PLoS One 8:e60007

3. Bull M, Plummer S, Marchesi J, Mahenthiralingam E (2013) The life history of Lactobacillus acidophilus as a probiotic, a tale of revisionary taxonomy, misidentification and commercial success. FEMS Microbiol Lett 349:77-87

4. Campelo AB, Roces C, Mohedano ML, López P, Rodríguez A, Martínez B (2014) A bacteriocin gene cluster able to enhance plasmid maintenance in Lactococcus lactis. Microb Cell Fact 13:77

5. Cebrián R, Rodríguez-Ruano S, Martínez-Bueno M, Valdivia E, Maqueda M, Montalbán-López M (2014) Analysis of the promoters involved in enterocin AS-48 
expression. PLoS One 9:e90603

6. Chen Z, Lin J, Ma C, Zhao S, She Q, Liang Y (2014) Characterization of pMC11, a plasmid with dual origins of replication isolated from Lactobacillus casei MCJ and construction of shuttle vector with each replicon. Appl Microbiol Biotechnol 98:5977-5989

7. De Vos WM (1987) Gene cloning and expression in lactic streptococci. FEMS Microbiol Rev 46:281-295

8. Dobson A, Cotter PD, Ross RP, Hill C (2012) Bacteriocin production, a probiotic trait? Appl Environ Microbiol 78:1-6

9. Duong T, Miller MJ, Barrangou R, Azcarate-Peril MA, Klaenhammer TR (2010) Construction of vectors for inducible and constitutive gene expression in Lactobacillus. Microb Biotech 4:357-367

10. Fekete RA, Miller MJ, Chattoraj DK (2003) Fluorescently labeled oligonucleotide extension, a rapid and quantitative protocol for primer extension. Biotechniques 35:90-98

11. García-Cayuela T, Gómez de Cadiñanos LP, Mohedano ML, Fernández de Palencia P, Boden D, Wells J, Peláez C, López P, Requena T (2012) Fluorescent protein vectors for promoter analysis in lactic acid bacteria and Escherichia coli. Appl Microbiol Botechnol 96:171-181

12. Gasson MJ (1983) Plasmid complements of Streptococcus lactis and other lactic streptococci after protoplast-induced curing. J Bacteriol 154:1-9

13. Hanahan D (1985) Techniques for transformation of E. coli. In: Glover DM (ed) DNA cloning, a practical approach, vol 1. IRL, Oxford, pp 109-135

14. Israelsen H, Madsen SM, Vrang A, Hansen EB, Johansen E (1995) Cloning and partial characterization of regulated promoters from Lactococcus lactis Tn917-lacZ 

integrants with the new promoter probe vector, pAK80. Appl Environ Microbiol $61: 2540-2547$

15. Kleerebezem M, Beerthuyzen MM, Vaughan EE, De Vos WM, Kuipers O (1997)

Controlled gene expression systems for lactic acid bacteria, transferable nisininducible expression cassettes for Lactococcus, Leuconostoc, and Lactobacillus spp. Appl Environ Microbiol 63:4581-4584

16. Kuipers OP, De Rayter PG, Kleerebezem M, De Vos WM (1998) Quorum sensingcontrolled gene expression in lactic acid bacteria. J Biotechnol 64:15-21

17. Lacks S (1968) Genetic regulation of maltosaccharide utilization in Pneumococcus. Genetics 60:685-706

18. Lacks SA, Greenberg B (2001) Constitutive competence for genetic transformation in Streptococcus pneumoniae caused by mutation of a transmembrane histidine kinase. Mol Microbiol 42:1035-1045

19. Lacks SA, López P, Greenberg B, Espinosa M (1986) Identification and analysis of genes for tetracycline resistance and replication functions in the broadhost-range plasmid pLS1. J Mol Biol 192:753-765

20. Maldonado-Barragán A, Caballero-Guerrero B, Lucena-Padrós H, Ruiz-Barba JL (2013) Induction of bacteriocin production by coculture is widespread among plantaricin-producing Lactobacillus plantarum strains with different regulatory operons. Food Microbiol 33:40-47

21. Mohedano ML, Overweg K, De la Fuente A, Reuter M, Altabe S, Mulholland F, De Mendoza D, López P, Wells J (2005) Inducible expression of the essential response regulator YycF in Streptococcus pneumoniae modulates expression of genes involved in fatty acid biosynthesis and affects membrane composition. J Bacteriol $178: 2357-2367$ 
22. Sambrook J, Russell DW (2001) Molecular cloning, a laboratory manual. Cold Spring Harbor laboratory, Cold Spring Harbor

23. Tabasco R, García-Cayuela T, Peláez C, Requena T (2009) Lactobacillus acidophilus La-5 increases lactacin B production when it senses live target bacteria. Int J Food Microbiol 132:109-116

24. Van Baarlen P, Wells JM, Kleerebezem M (2013) Regulation of intestinal homeostasis and immunity with probiotic lactobacilli. Trends Immunol 34:208-215

25. Wang A, Yu H, Gao X, Li X, Qiao S (2009) Influence of Lactobacillus fermentum I5007 on the intestinal and systemic immune responses of healthy and E. coli challenged piglets. Antonie Van Leeuwenhoek 96:89-98

26. Wells JM (2011) Mucosal vaccination and therapy with genetically modified lactic acid bacteria. Ann Rev Food Sci Technol 2:423-445 


\section{$376 \quad$ Legend to the Figures}

377 Figure 1. Schematic diagram showing the construction of pRCR and pRCR11. For

378 details, see "Materials and methods". Relevant restriction sites are shown. Specific

379 genes are: $m r f p$ and cat that encode mCherry and the protein responsible for the

380 resistance to chloramphenicol, respectively. $P_{l b a B}$, promoter of the lactacin B structural

381 gene of Lactobacillus acidophilus La5.

382

383 Figure 2. Detection of induction of expression of mCherry encoded by pRCR11.

384 Fluorescence (relative fluorescence units, RFU; triangles) and growth ( $\mathrm{OD}_{600}$; circles)

385 of cultures of L. acidophilus CECT 903[pRCR11] (open symbols) and co-cultures of $L$.

386 acidophilus CECT 903[pRCR11] and Streptococcus thermophilus STY-31 (closed

387 symbols) grown in MRSCT are depicted. The growth of cultures was monitored at a

388 wavelength of $600 \mathrm{~nm}$. Fluorescence emission of mCherry was recorded at $612 \mathrm{~nm}$ after

389 excitation at a wavelength of $587 \mathrm{~nm}$.

Figure 3. Detection of the start site of the $l b a B$ transcript by primer extension. Reactions containing total RNA isolated from cultures of L. acidophilus CECT 903[pRCR11] alone or in co-culture with S. thermophilus STY-31 were analyzed by capillary electrophoresis in conjunction with DNA sequence of pRCR11 (A) or by $8 \%$ denaturating polyacrylamide gel electrophoresis (B). For primer extension and DNA sequence analysis were used, respectively, primers fluorescently labeled at the $5^{\prime}$-end with 6-FAM, or unlabelled (both having the same DNA sequence). Extended products ran as if they were, on an average, three nucleotides shorter than the dideoxy sequencing products. The length of the extended products determined by the analysis depicted in 
400 (A) is indicated in the analysis showed in (B).The DNA region surrounding the start site 401 of the mRNA is also depicted (C). The start sites of the transcript detected in (A) are 402 indicated by stars. The -35 and -10 regions of the $P_{l b a B}$ promoter are shown. The 403 inverted repeat, putative binding site of the RR_1798 response regulator, is indicated by 404 arrows. 
Figure 1
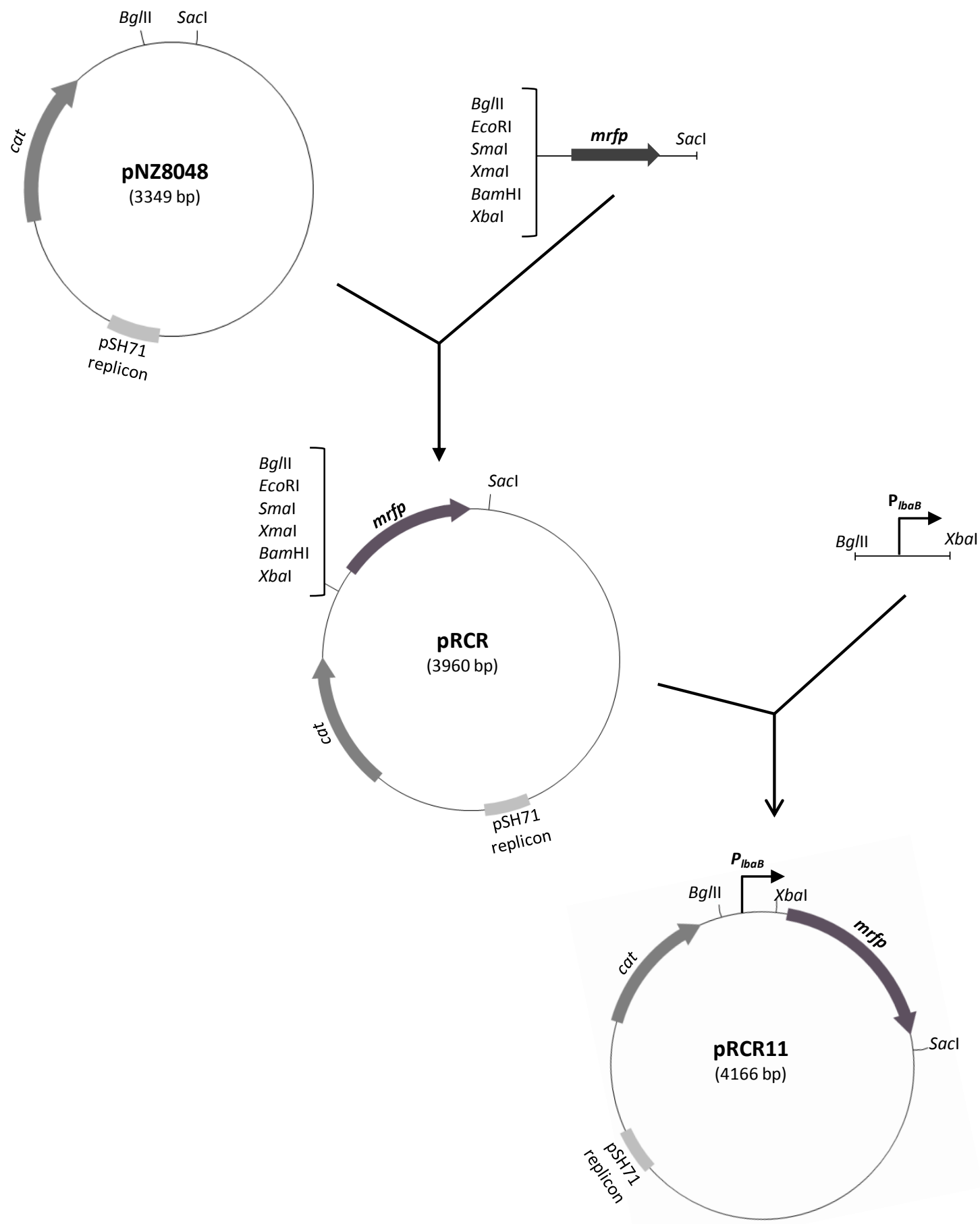

Figure 1 


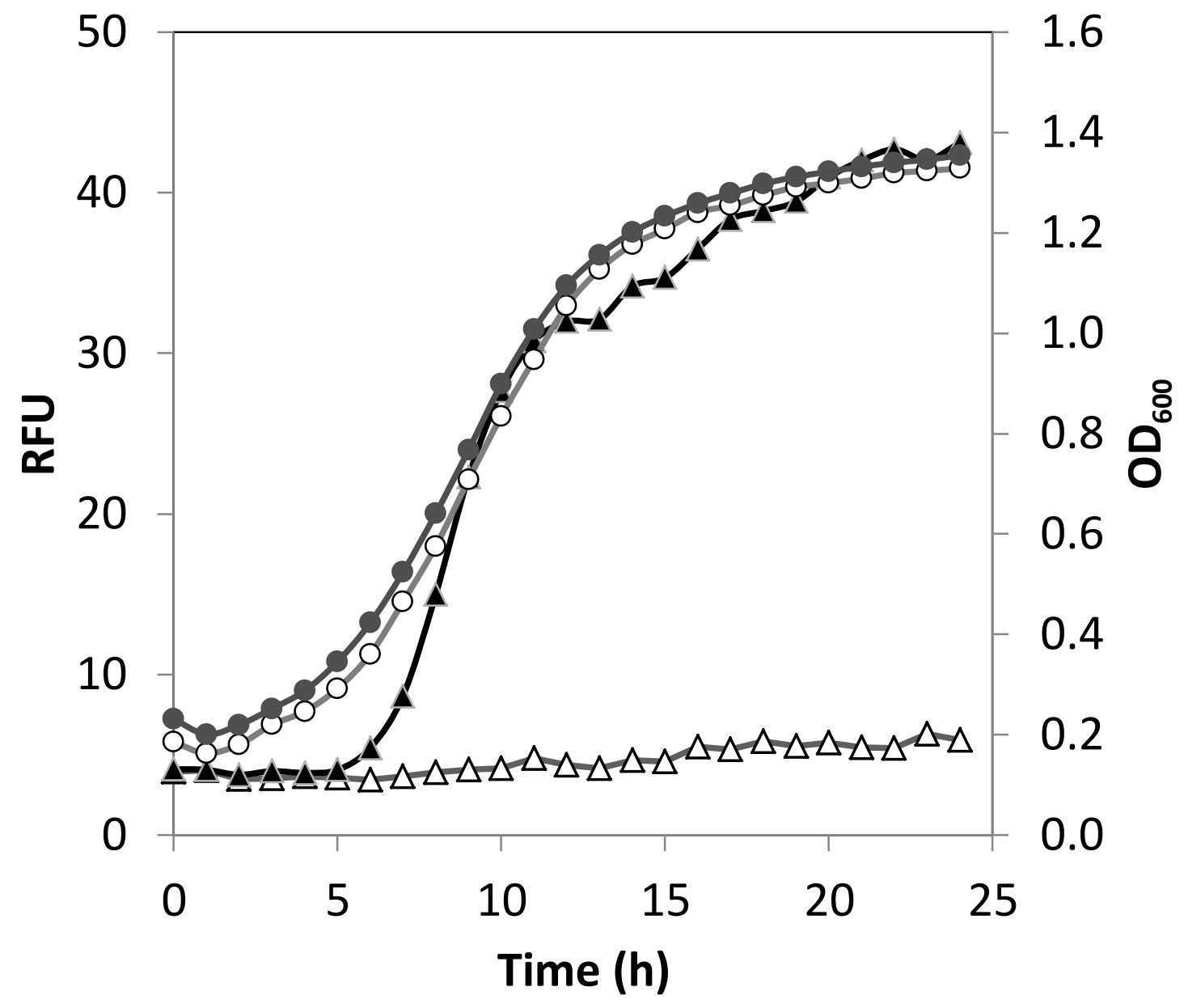

Figure 2 
A

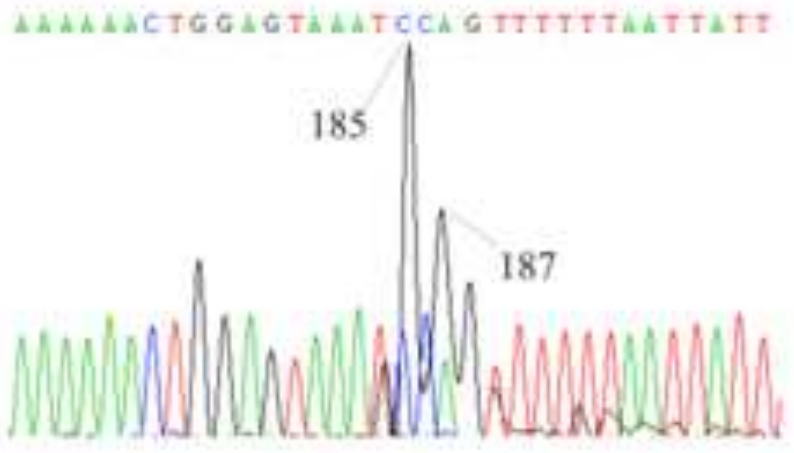

L. acidophihus CECT903 [pRCR11] and S. thermophilus STY-31

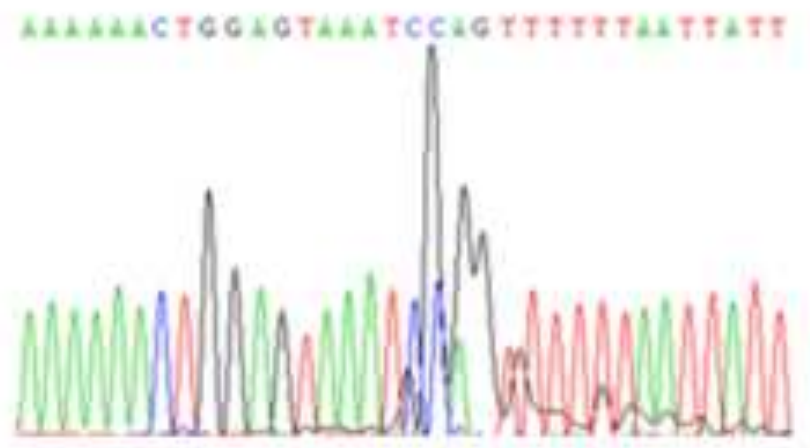

L. acidophilus CECT903 [pRCRI1]

B

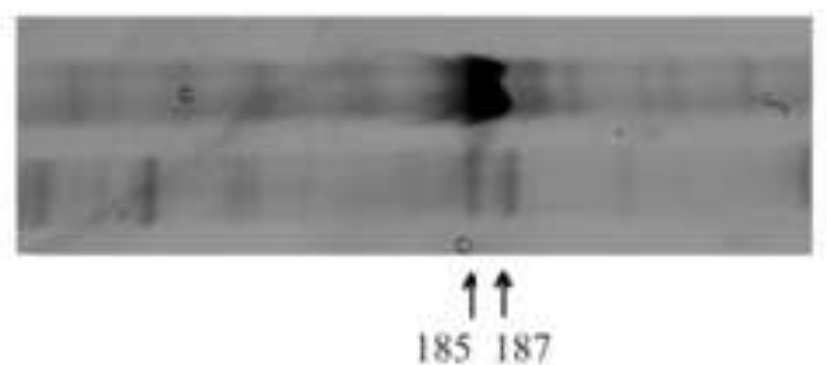

L. acidophilus CECT903 [pRCR11] and S. thermophilus STY-31

L. acidophilus CECT903 [pRCRI1]

C

TTGTAA- 24 nt -AATAATTAAAAAACTGGATTTACTCCAGTTTTTT AACATT - 24 nt -TTATTAATTTTTTGACCTAAATGAGGTCAAAAAA 